Mycologia, 106(1), 2014, pp. 57-65. DOI: 10.3852/13-043

(C) 2014 by The Mycological Society of America, Lawrence, KS 66044-8897

\title{
A high-temperature tolerant species in clade 9 of the genus Phytophthora: $P$. hydrogena sp. nov.
}

Xiao Yang ${ }^{1}$

Department of Plant Pathology, Physiology and Weed Science, Hampton Roads Agricultural Research and Extension Center, Virginia Polytechnic Institute and State University, Virginia Beach, Virginia 23455

Mannon E. Gallegly

Division of Plant and Soil Sciences, West Virginia University, Morgantown, West Virginia 26506

Chuanxue Hong

Department of Plant Pathology, Physiology and Weed Science, Hampton Roads Agricultural Research and Extension Center, Virginia Polytechnic Institute and State University, Virginia Beach, Virginia 23455

Abstract: A previously unknown Phytophthora species was isolated from irrigation water in Virginia, USA. This novel species produces abundant noncaducous and nonpapillate sporangia in soil water extract solution. It sometimes produces chlamydospores and hyphal swellings in aged cultures and in Petri's solution. This species has optimum vegetative growth at $30 \mathrm{C}$ and grows well at $35 \mathrm{C}$. The lowest and highest temperatures for growth are 5 and $40 \mathrm{C}$. All isolates examined in this study are compatibility type A1 and produce mostly plerotic oospores when paired with an A2 mating-type tester of $P$. cinnamomi. Sequence analyses of the rDNA internal transcribed spacer (ITS) regions and the mitochondrially encoded cytochrome $c$ oxidase $1\left(\begin{array}{lll}\operatorname{cox} 1 & 1\end{array}\right)$ gene placed this species in clade 9 of the genus Phytophthora. These characteristics support the description of this taxon as a new species for which we propose the name $P$. hydrogena sp. nov. Further phylogenetic and physiological investigations of clade 9 species revealed a high-temperature tolerant cluster including $P$. hydrogena, $P$. aquimorbida, $P$. hydropathica, $P$. irrigata, $P$. chrysanthemi, $P$. insolita, $P$. polonica and $P$. parsiana. These species all grow well at $35 \mathrm{C}$. The monophyly of the species in this heat-tolerant cluster except $P$. insolita and $P$. polonica is highly supported by the maximum-likelihood analyses of the ITS and $\operatorname{cox} 1$ sequences.

Key words: clade 9, high-temperature tolerance, irrigation water, Phytophthora hydrogena

Submitted 1 Feb 2013; accepted for publication 26 Jun 2013.

${ }^{1}$ Corresponding author. E-mail: yxiao9@vt.edu

\section{INTRODUCTION}

Many species in the genus Phytophthora have been considered destructive plant pathogens. Two notorious examples are that $P$. infestans caused Irish potato famine 1845-1849 (Erwin and Ribeiro 1996) and $P$. ramorum caused sudden oak death (SOD), which has killed millions of trees in the forests of Oregon and California (Goheen et al. 2002, Rizzo et al. 2002). The SOD disaster reminded the science community and the public of the constant plant biosecurity threat posed by Phytophthora species and invigorated research in these pathogens (Grüenwald et al. 2012). To date the total number of formally described Phytophthora species has reached 120, which is double the number 17 y ago (Erwin and Ribeiro 1996).

Traditional taxonomy of Phytophthora species was based on morphological characteristics, as exemplified by the classic morphological key by Waterhouse (1963), which separated the genus into six groups and is still widely used today. However, due to the plasticity and overlapping of morphological characteristics among species, taxonomy based on morphology cannot be used to reliably distinguish some species within the genus (Erwin and Ribeiro 1996, Naher et al. 2011).

Phylogenetic analyses of various DNA regions have greatly advanced the taxonomy of this important genus. Ten clades were proposed for genus Phytophthora after phylogenetic analyses of mitochondrial and nuclear DNA sequences (Cooke et al. 2000, Martin and Tooley 2003, Kroon et al. 2004, Villa et al. 2006, Blair et al. 2008, Robideau et al. 2011). By taking advantage of the phylogenetic analyses, many new species have been separated from some well known species complexes. For instance, $P$. brassicae (Man in 't Veld et al. 2002) was separated from $P$. porri. P. obscura (Grüenwald et al. 2012) was separated from $P$. syringae. Similarly $P$. hydropathica (Hong et al. 2010) and P. irrigata (Hong et al. 2008) were separated from $P$. drechsleri. Likewise $P$. plurivora (Jung and Burgess 2009) and P. pini (Hong et al. 2011) were separated from $P$. citricola. In addition, many new species, such as $P$. aquimorbida (Hong et al. 2012), P. bilorbang (Aghighi et al. 2012), P. borealis and $P$. riparia (Hansen et al. 2012), were discovered.

Among the 10 Phytophthora clades, clade 9 contains many relatively new members. The only exceptions are P. insolita (Ann and Ko 1980), P. macrochlamydospora (Irwin 1991) and P. quininea (Crandall 1947). All other species in this clade were described after 2005. Many 
members in this clade, such as three recently named species P. irrigata (Hong et al. 2008), P. hydropathica (Hong et al. 2010) and P. aquimorbida (Hong et al. 2012), are well adapted to the irrigation reservoir environment. The objective of this study was to examine another group of water isolates with distinct features and formally describe it as Phytophthora hydrogena sp. nov.

\section{MATERIALS AND METHODS}

Isolation and isolate maintenance.-Three isolates examined in this study (TABLE I) were recovered by baiting with fresh rhododendron or camellia leaves (Hong et al. 2002, Bush et al. 2003, Ghimire et al. 2011) from irrigation reservoirs in an ornamental plant nursery in Virginia, USA, in May and Oct 2007. Cultures were grown on 20\% clarified V8 juice agar (CV8A) (Erwin and Ribeiro 1996), and blocks of fresh agar cultures were transferred into microtubes with sterile distilled water for long-term storage at $15 \mathrm{C}$. The ex-type was deposited at the American Type Culture Collection (MYA-4919) in Manassas, Virginia. The dry culture as holotype was deposited at the Massey Herbarium of Virginia Polytechnic Institute and State University (VTMH 14882) in Blacksburg, Virginia.

Colony morphology.- To examine colony morphology, cultures were grown on CV8A, carrot agar (CA), malt extract agar (MEA) and potato dextrose agar (PDA). Each $10 \mathrm{~cm}$ Petri dish with $12 \mathrm{~mL}$ medium was seeded upside down with an agar block ( $5 \mathrm{~mm}$ diam) taken from $10 \mathrm{~d}$ cultures with the aid of a flamed cork borer. The dishes were placed in the dark at 20 C. Colony morphology was noted after $10 \mathrm{~d}$.

DNA extraction, amplification and sequencing.-A $5 \times 5 \mathrm{~mm}$ agar plug from an actively growing culture was placed in 20\% V8 juice broth (Erwin and Ribeiro 1996) at room temperature (ca. $23 \mathrm{C}$ ) for $7 \mathrm{~d}$ to produce mycelial mass. The mycelial samples were harvested, dried and lysed with a FastPrep ${ }^{\circledR}$-24 system (MP Biomedicals, Santa Ana, California). Purified DNA was extracted as instructed with the DNeasy ${ }^{\circledR}$ Plant Mini Lit (Qiagen, Valencia, California). Amplifications were performed with forward primer ITS6 and reverse primer ITS4 (Cooke et al. 2000) for the internal transcribed spacer (ITS) region covering ITS1, 5.8S rRNA gene and ITS2, following previously described reaction mix recipe and PCR program (Kong et al. 2003). Amplifications also were performed with primer pair COX4FR (Kroon et al. 2004) for sequencing the mitochondrially encoded cytochrome $c$ oxidase 1 gene ( $\operatorname{cox} 1$ ) following the PCR protocol with a $45 \mathrm{C}$ annealing temperature. Excess primer and dNTPs were removed from PCR products with shrimp alkaline phosphatase and exonuclease I (USB 70092Y and 70073Z). One U each enzyme was added to $15 \mathrm{~mL}$ PCR product, incubated at $37 \mathrm{C}$ for $30 \mathrm{~min}$, followed by heat inactivation at $65 \mathrm{C}$ for $15 \mathrm{~min}$. Sequencing was performed in both directions for all regions with the same primers as for PCR by the University of Kentucky Advanced Genetic Technologies Center (Lexington, Kentucky). Sequences of both directions were viewed with Finch TV 1.4.0. and aligned with Clustal W.

Phylogenetic analysis. - Sequences generated in this study were compared with those of all other species in the same clade and selected species in other clades (TABLE I). Sequences were aligned with Clustal W. Phylogeny reconstruction was conducted in MEGA 5 (Tamura et al. 2011) with the maximum-likelihood method based on the Tamura-Nei model (Tamura and Nei 1993) with 1000 bootstrap replications. GenBank accession numbers of the sequences derived in this study are provided (TABLE I). The alignments and trees are available in TreeBASE (S14412).

Growth temperature studies.-Three isolates were assessed for cardinal temperatures on CV8A and CA. Agar blocks (5 mm diam) taken from actively growing areas of $10 \mathrm{~d}$ cultures were placed at the center of Petri dishes with fresh media. These dishes were placed in the dark at 5, 10, 15, 20, $25,30,35,36,37,38,39$ or $40 \mathrm{C}$, triplicate dishes per isolate per temperature. Two perpendicular diameter measurements of each colony were taken when the margin of the fastest growing colony was about $1 \mathrm{~cm}$ from the dish edge. The test was repeated. Means of radial growth along with standard errors were plotted against temperature with the gplots package 2.11.0 (Warnes et al. 2012) in R statistical software 2.15.0 (R Core Team 2012).

Sporangial morphology.- Sporangia were produced by transferring $10 \times 10 \mathrm{~mm}$ square agar plugs of $1-2 \mathrm{wk}$ old colonies on $10 \%$ CV8A to Petri dishes containing non-sterile $1.5 \%$ soil water extract solution (SWE, $15 \mathrm{~g}$ non-Phytophthora containing nature soil/1 L distilled water) and incubating at room temperature approximately $10 \mathrm{~h}$ until mature sporangia formed. Sporangia were photographed with a Nikon Fujix Digital Camera HC-300Zi connected to a Nikon Labophot-2 microscope. At least 50 randomly selected mature sporangia were measured for length and width with Image-Pro ${ }^{\circledR}$ Plus 5.1.2.53.

Breeding system of gametangia.-Because gametangia were not observed in single cultures on any media, several methods were employed to determine the sexuality and mating type of three isolates of $P$. hydrogena. They were tested in dual culture with either A1 or A2 mating type tester of P. cinnamomi on hemp seed agar (HSA) or CV8A. Also, the polycarbonate technique (Ko 1978, Gallegly and Hong 2008) was used to induce selfing and prevent mixing the gametangia of target isolates and testers. Specifically, each isolate was paired with either mating type of $P$. cinnamomi on CA or HSA amended with $30 \mathrm{mg} \beta$-sitosterol $\mathrm{L}^{-1}$ then incubated at 20 and $25 \mathrm{C}$ as well as room temperature. For isolates that did not produce oospores, additional tests were conducted with the mating type testers of $P$. meadii and P. cambivora at the same temperatures.

Statistical analysis. - Analyses of variances were carried out with $\mathrm{R}$ ( R Core Team 2012) to determine the differences in the measurements of morphological and physiological characteristics among repeating experiments and isolates.

\section{RESUlTS}

Colony morphology. - After growing at $20 \mathrm{C}$ in dark for $10 \mathrm{~d}$, three isolates of $P$. hydrogena showed a similar growth pattern (FIG. 1). Overall, colonies expanded 
YANG ET AL.: PHYTOPHTHORA HYDROGENA SP. NOV.

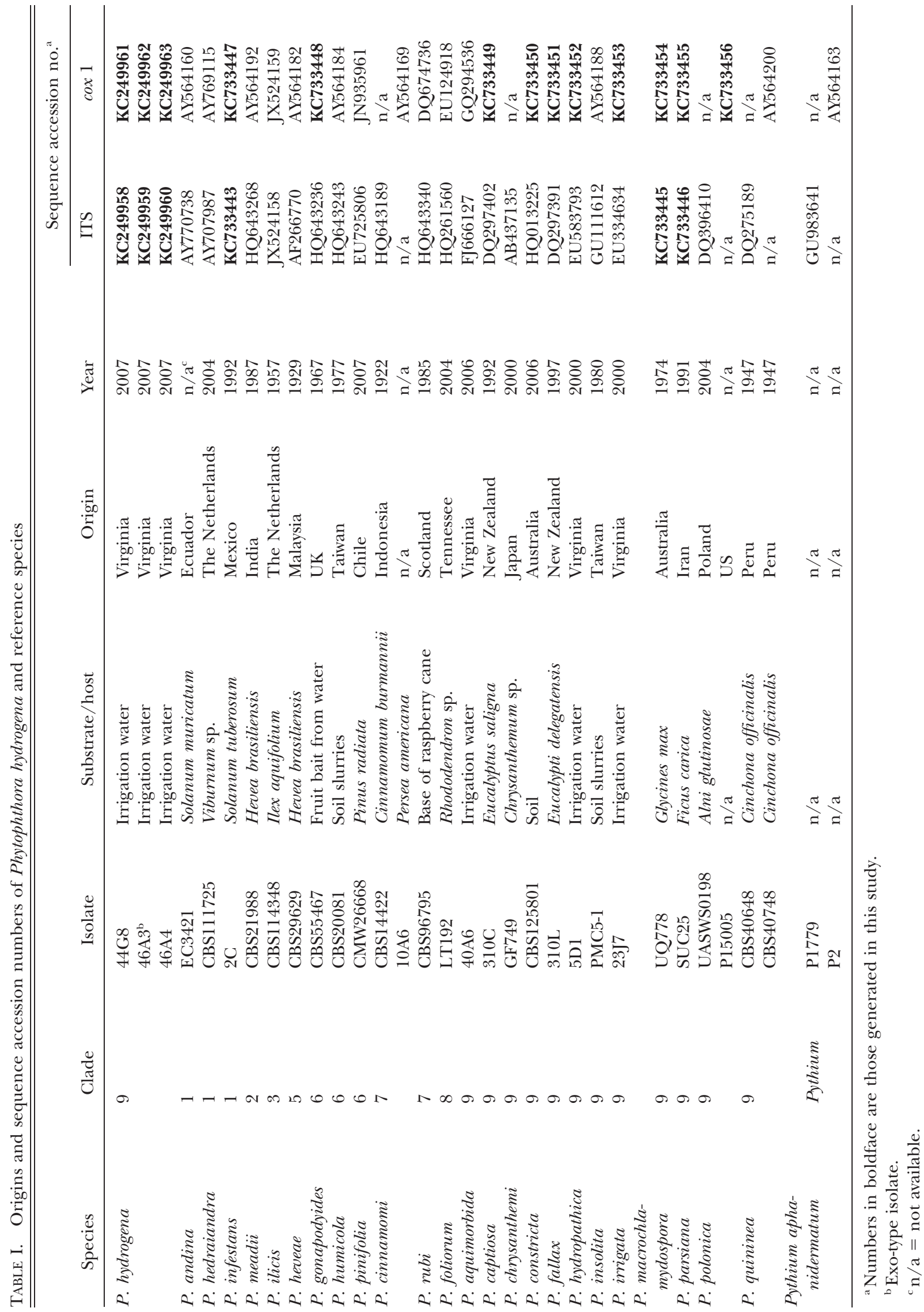




\section{$\begin{array}{llll}\text { CA } & \text { CV8A } & \text { MEA } & \text { PDA }\end{array}$}

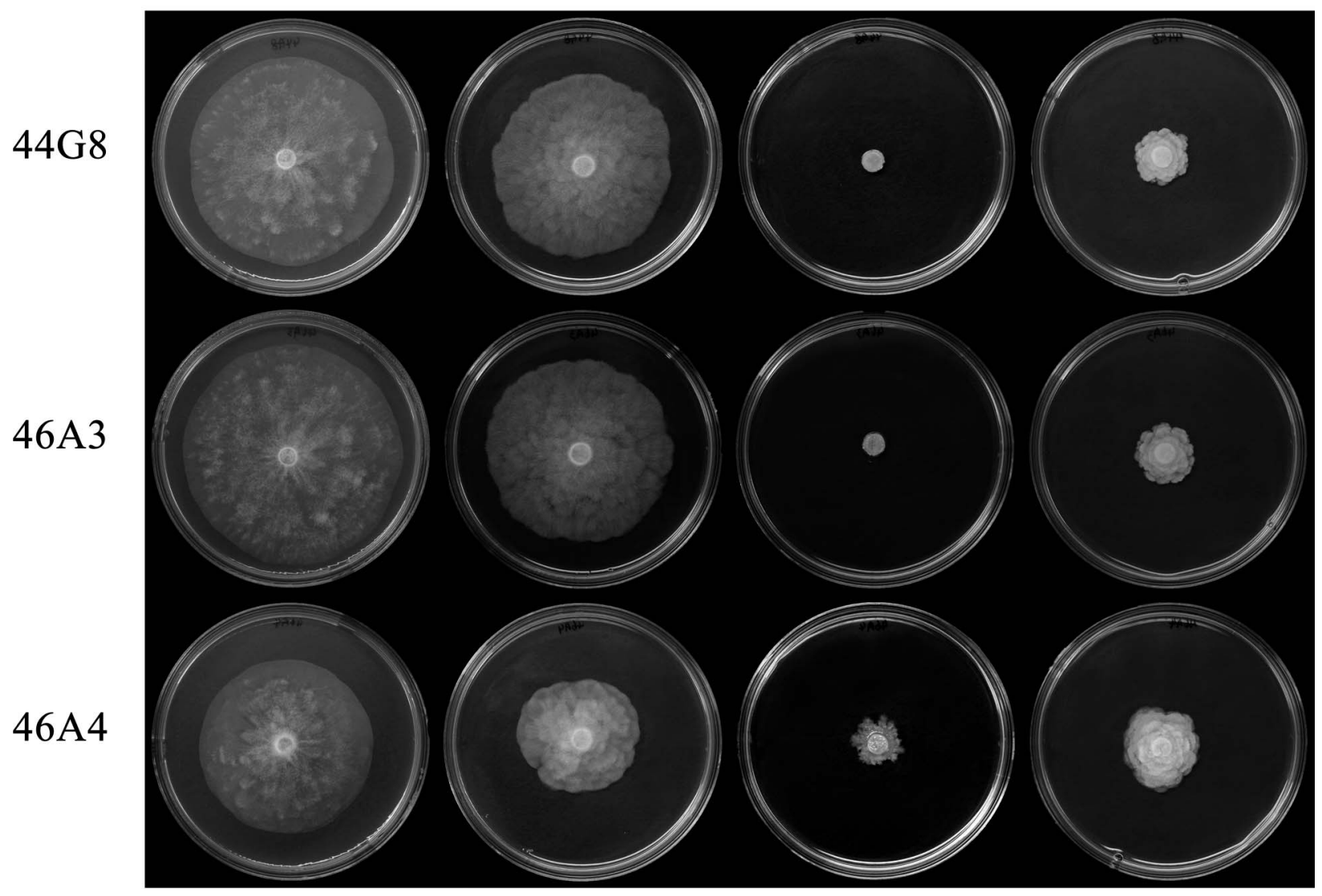

FIG. 1. Colony morphology of Phytophthora hydrogena isolates on various media incubated at $20 \mathrm{C}$ for $10 \mathrm{~d}$ in the dark. $\mathrm{CA}=$ carrot agar, CV8A $=20 \%$ clarified V8 juice agar, MEA $=$ malt extract agar, PDA $=$ potato dextrose agar.

the fastest on CA among four tested media. Colonies on CA had a relatively smooth edge and produced radiate to slightly chrysanthemum-like patterns. On CV8A and PDA, all isolates formed typical chrysanthemum-like colonies with irregular edges, although colonies expanded more slowly and were denser on PDA than on CV8A. Only isolate 46A4 had limited but discernible growth with irregular colony and radiate mycelia on MEA (FIG. 1).

Sequence analysis and phylogenetic position.-Three isolates of $P$. hydrogena have an identical 744 bp ITS sequence and an identical 867 bp partial cox 1 sequence. $P$. hydrogena is placed within Phytophthora clade 9 , according to the maximum-likelihood phylogenetic trees based on ITS and cox 1 sequences (Blair et al. 2008). It forms a distinct new group with its closest relatives $P$. hydropathica, $P$. irrigata and $P$. parsiana, with strong bootstrap support (FIG. 2). $P$. hydrogena differs in ITS sequence from $P$. hydropathica, $P$. irrigata and $P$. parsiana by $31 \mathrm{bp}, 53 \mathrm{bp}$ and $43 \mathrm{bp}$ respectively. In cox 1 sequence, $P$. hydrogena is different from $P$. hydropathica, $P$. irrigata and $P$. parsiana by $25 \mathrm{bp}, 28 \mathrm{bp}$ and $26 \mathrm{bp}$ respectively.

Cardinal temperatures for vegetative growth. - Vegetative growth rates were statistically identical among three isolates $(P=0.98)$ and between two experiments $(P=0.26)$. The average daily radial growth of three isolates were plotted against temperature (FIG. 3). Generally, P. hydrogena grew discernibly faster on CA than on CV8A. The optimum temperature for growth was $30 \mathrm{C}$ and it grew well at $35 \mathrm{C}$ (FIG. 3). Only notable growth was observed at 38 and $39 \mathrm{C}$ and no growth at 5 and $40 \mathrm{C}$ after $5 \mathrm{~d}$ (FIG. 3).

\section{TAXONOMY}

Phytophthora hydrogena X. Yang and C. X. Hong., sp. nov.

FIG. 4

MycoBank MB803274

Phytophthora hydrogena produced few sporangia in aged CA and CV8A. When mycelial plugs were submerged in $1.5 \%$ SWE under light, they produced abundant sporangia within $10 \mathrm{~h}$. Sporangia varied 

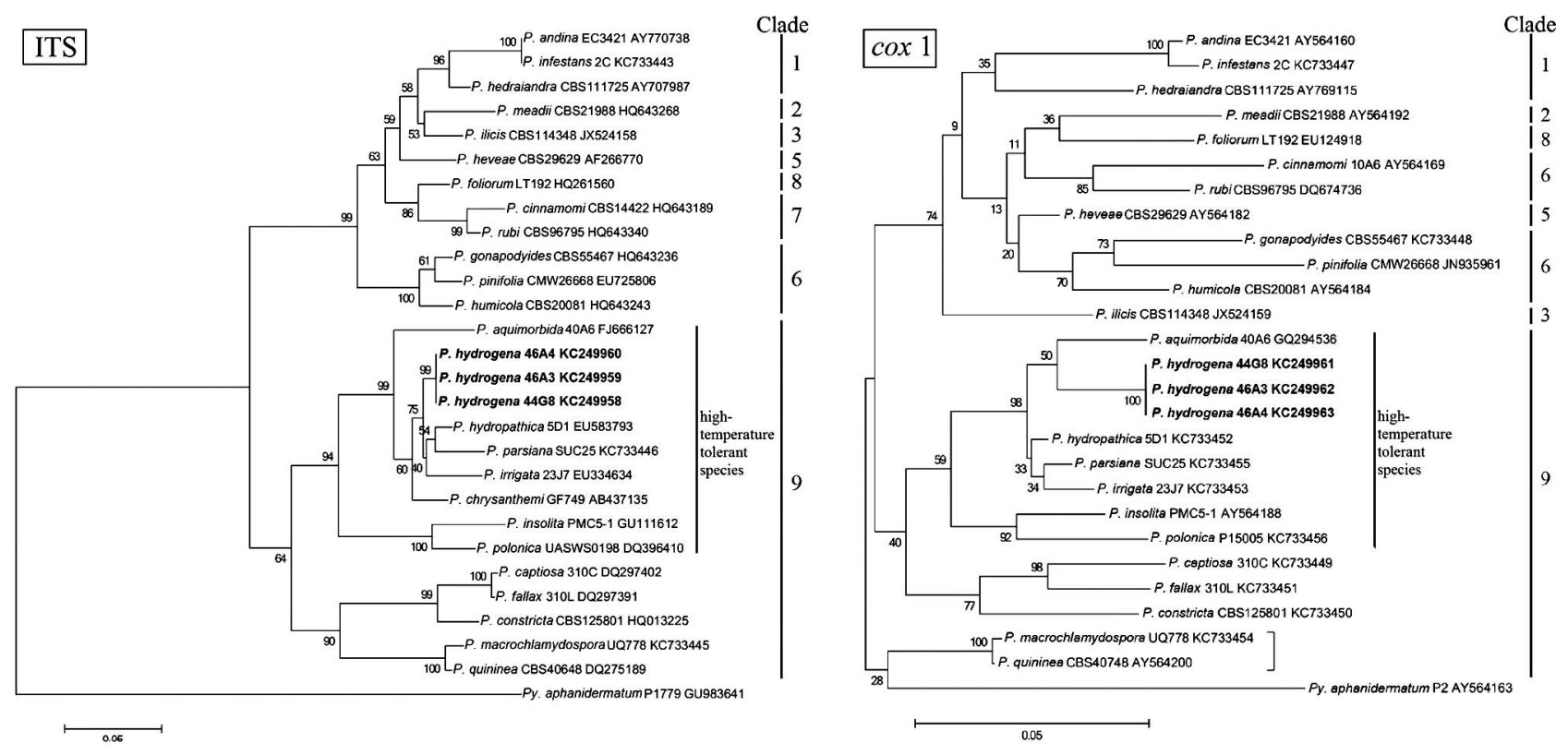

FIG. 2. Maximum likelihood phylogenetic trees based on ITS and cox 1 sequences. Alignment was conducted with Clustal $\mathrm{W}$, and the phylogenetic tree was generated in MEGA 5.

from ovoid to obpyriform, limoniform and ellipsoid (FIG. 4A-G). Sporangia were terminal, nonpapillate and noncaducous; they averaged $44.58 \mu \mathrm{m}$ long and $29.27 \mu \mathrm{m}$ wide. Most sporangia had a conspicuous cell wall at the joint point between sporangial base and pedicel tip. Approximate half of the sporangia observed in this study had characteristic widening at the pedicel tip of sporangiophores or tapered sporangial base toward the point of attachment (FIG. 4K-M). Sporangia also commonly had a conspicuous basal plug (FIG. 4H, K). Nested and extended internal proliferation (FIG. 4I, J) was common. Knobby and angular mycelia were observed especially in aged cultures (FIG. 4S, T). Hyphal swelling of sporangiophores (FIG. 4P, R) occasionally was observed when submerged in modified Petri's solution. Chlamydospores were not observed in fresh culture on any agar media or in SWE. However, a limited

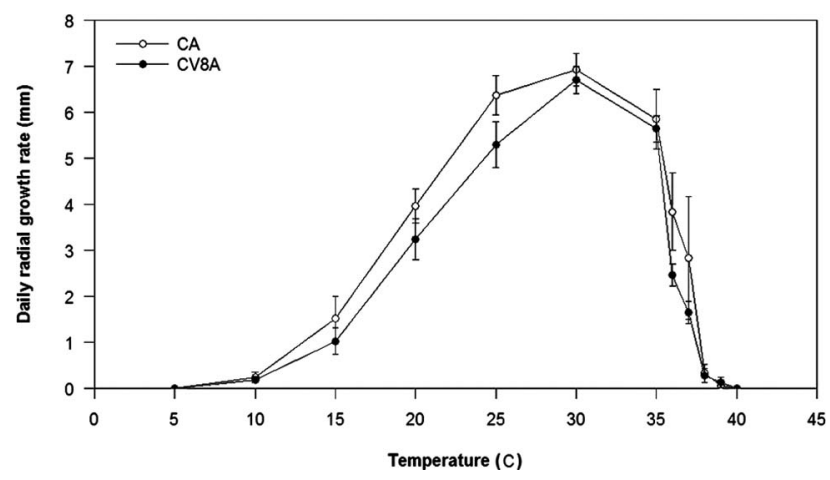

FIG. 3. Radial growth of Phytophthora hydrogena isolates in carrot agar (CA) and 20\% clarified V8 juice agar (CV8A) over a $5 \mathrm{~d}$ period. number of chlamydospores, average $34.5 \mu \mathrm{m}$ diam, were observed in aged cultures $(>50 \mathrm{~d})$ in CA and CV8A or cultures incubated in modified Petri's solution for more than $12 \mathrm{~h}$ under light (FIG. 4N, O).

Phytophthora hydrogena is heterothallic and all examined isolates are A1. None of these isolates produced any sexual structure in single culture. Polycarbonate membrane tests on CA and HSA at 20, $25 \mathrm{C}$ and room temperature induced the formation of gametangia in A2 tester isolates of $P$. cambivora and $P$. cinnamomi. Gametangia were not observed in any isolates of $P$. hydrogena or testers of $P$. meadii. Gametangia also were observed when each $P$. hydrogena isolate was paired with an A2 tester of $P$. cambivora or $P$. cinnamomi in the dual culture without separation by a polycarbonate membrane. Most of the oogonia produced in the dual cultures were typical of $P$. cinnamomi, which had a funnel-shaped base or broad, tapering stalk through an antheridium (Gallegly and Hong 2008; FIG. 5I). A small number of oogonia were distinct from those typical oogonia produced by $P$. cinnamomi. They most likely were produced by $P$. hydrogena (FIG. 5A-H). These oogonia were globose with golden to brown pigment, averaged $41.1 \mu \mathrm{m}$ diam. Oospores, average $37.6 \mu \mathrm{m}$, were mostly plerotic (FIG. 5A-C, E, F), sometimes aplerotic (FIG. 5D, G) and eccentric (FIG. 5G). These oogonia were attached by antheridia that were mostly amphigynous and averaged about $15 \mu \mathrm{m}$ wide and deep (FIG. 5A-H). Multiple paragynous antheridia occasionally were associated with an oogonium (FIG. 5H).

Holotype: VTMH 14882 (Virginia Tech Massey Herbarium, Blacksburg, Virginia, USA), dried culture 


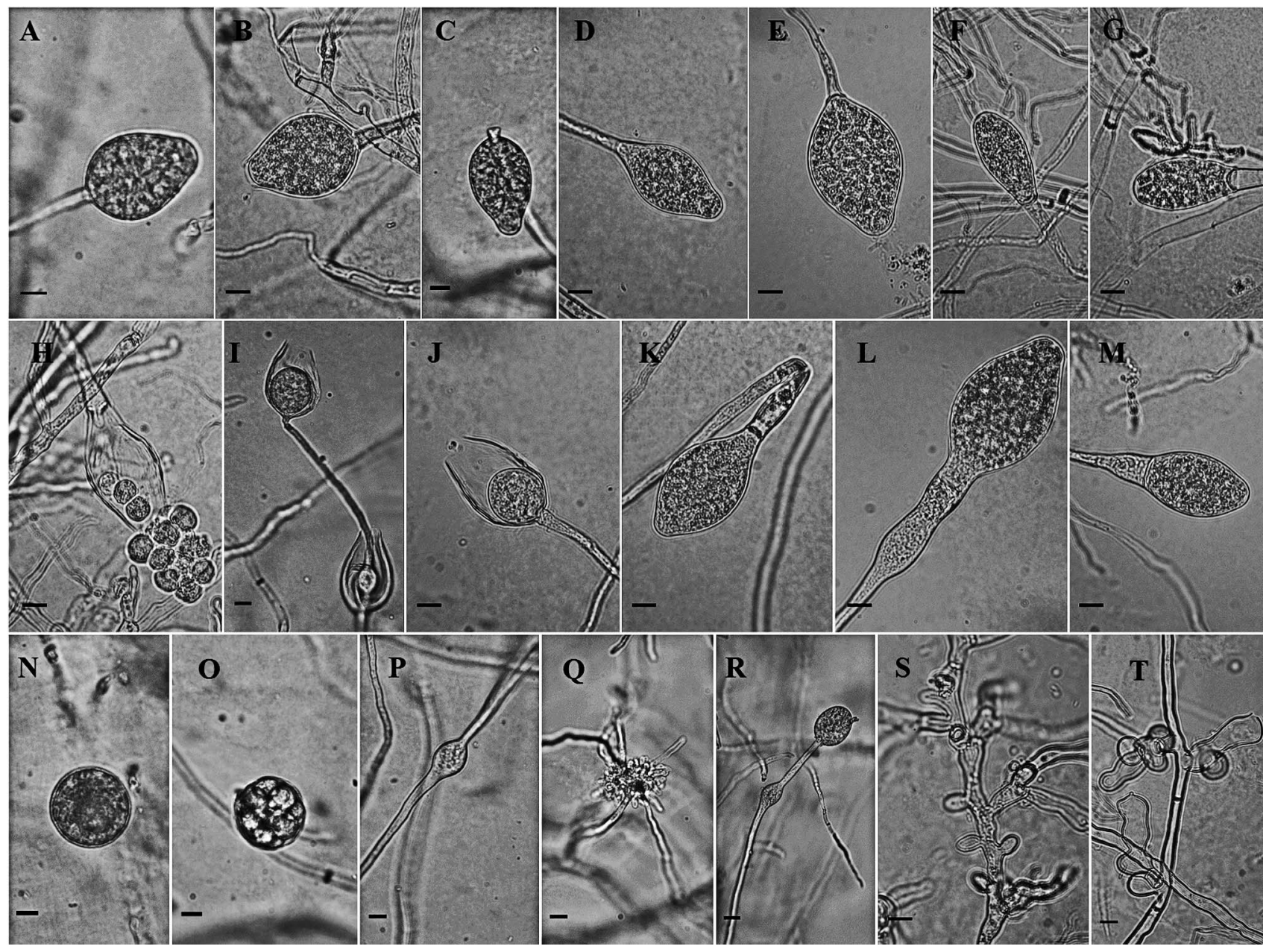

FIG. 4. Morphology of asexual structures of Phytophthora hydrogena. A-G. Nonpapillate sporangia in various shapes. A, B. Ovoid sporangia. C. An obpyriform to ovoid sporangium. D, E. Limoniform sporangia with a tapered base. F, G. Ellipsoid sporangia. H. A sporangium with a conspicuous basal plug releasing zoospores. I, J. Nested proliferation. K. A sporangium with a conspicuous basal plug, a tapered base and a widening sporangiophore tip. L, M. Sporangia with a tapered base and a widening sporangiophore tip. N, O. Chlamydospores infrequently produced in modified Petri's solution. P, R. Intercalary swelling on sporangiophore occasionally produced in modified Petri's solution. Q. Hyphal aggregation rarely formed in modified Petri's solution. S, T. Knobby and angular coralloid-like mycelia. Bars $=10 \mu \mathrm{m}$.

of an isolate from irrigation water of a nursery reservoir, Virginia, USA, Oct 2007. Ex-holotype: 46A3 (ATCG MYA-4919).

Etymology: "hydrogena" refers to the aquatic habitat where it was isolated.

Habitat: Irrigation water of a perennial plant nursery, Virginia, USA.

\section{DISCUSSION}

This study described a novel species, Phytophthora hydrogena, based on its distinct phylogenetic position, morphology and physiology, and revealed a cluster of high-temperature tolerant species within Phytophthora clade 9 . These findings have several ramifications.
Description of $P$. hydrogena is the first and critical step to assess the potential plant biosecurity threat posed by this species and also will help reduce the risk in misidentification of high-impact pathogens within this genus. $P$. hydrogena is morphologically, physiologically and phylogenetically distinct from any other known Phytophthora species. As a heterothallic species, $P$. hydrogena can be easily distinguished from homothallic species. Among heterothallic species, $P$. drechsleri, $P$. hydropathica, $P$. inundata, $P$. irrigata, $P$. melonis and $P$. parsiana as well as this new species, $P$. hydrogena, produce nonpapillate sporangia and grow well at $35 \mathrm{C}$ (Gallegly and Hong 2008, Hong et al. 2010). P. hydrogena differs from $P$. drechsleri, $P$. inundata, $P$. melonis, and $P$. parsiana by producing 

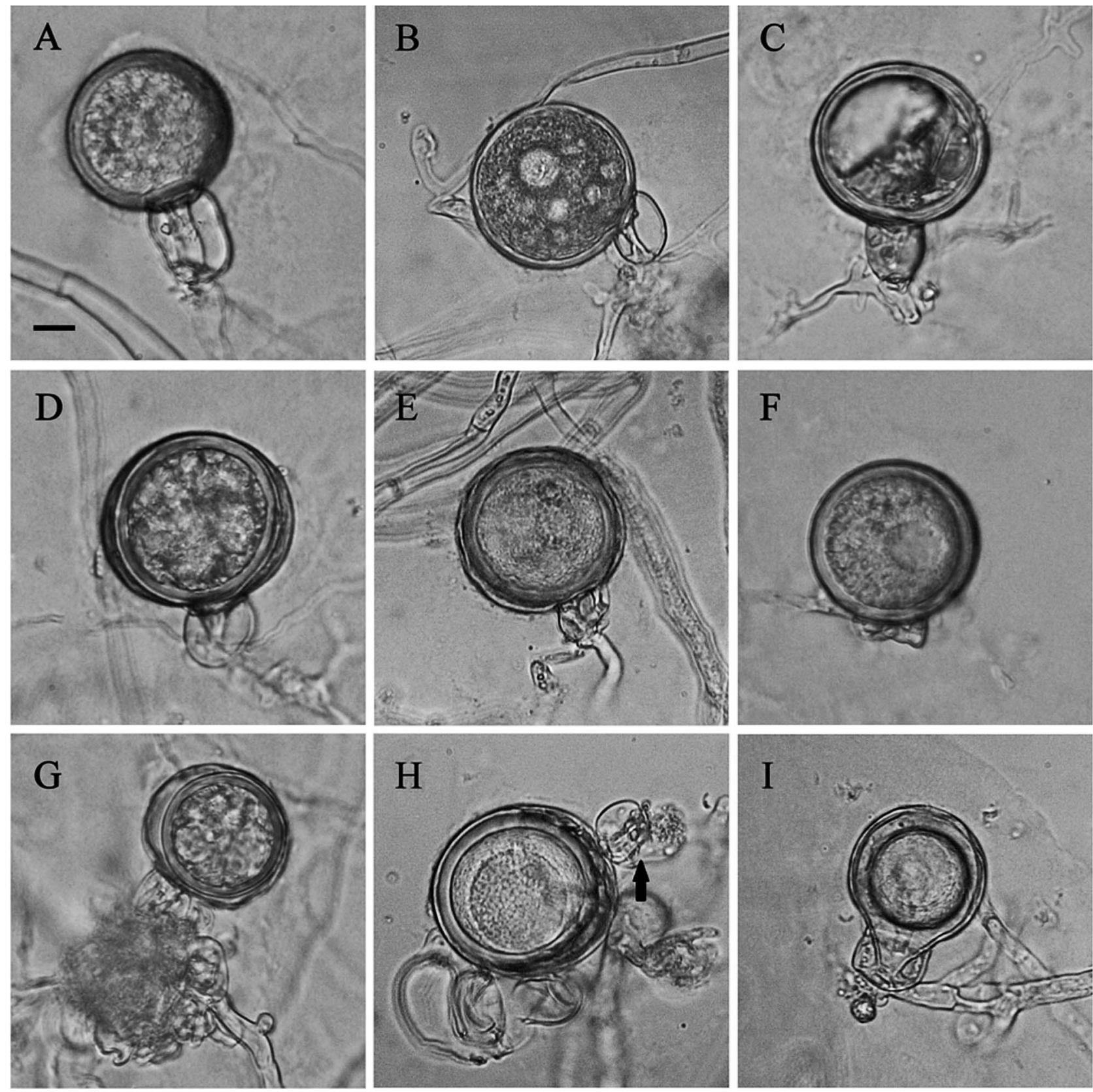

FIG. 5. Morphology of sexual organs of Phytophthora hydrogena. A. A plerotic oospore with a long, cylindroid, amphigynous antheridium. B. A plerotic oospore with a globose antheridium. C. A plerotic oospore with a golden coniform antheridium. D. A slightly aplerotic oospore with a globose antheridium. E, F. Plerotic oospores with a short antheridium. G. Excentric aplerotic oospore. H. A slight aplerotic oospore with an amphigynous antheridium (arrow) and multiple paragynous antheridia. I. A typical sexual organ produced by Phytophthora cinnamomi with a characteristic broad tapering stalk in the antheridium and a funnel-shaped base of the oogonium within the antheridium. Bar $=10 \mu \mathrm{m}$.

much smaller sporangia. It also differs from $P$. drechsleri, P. hydropathica, P. inundata, P. melonis and $P$. parsiana by not producing chlamydospores in CV8A, CA, MEA or PDA. Morphologically P. hydrogena is very similar to $P$. irrigate, but the former can be distinguished by its characteristic widening of sporangiophore tips and tapered sporangial bases.
Many species in Phytophthora clade 9 share a common physiological character of high-temperature tolerance. Analyses of ITS and cox 1 sequences grouped P. hydrogena with P. aquimorbida (Hong et al. 2012), P. hydropathica (Hong et al. 2010), P. irrigata (Hong et al. 2008), P. chrysanthemi (Naher et al. 2011) (only supported by ITS sequence), $P$. insolita (Ann and Ko 
1980), P. polonica (Belbahri et al. 2006) and P. parsiana (Mostowfizadeh-Ghalamfarsa et al. 2008) in a distinct cluster (FIG. 2). Species in this cluster have an optimum temperature around $30 \mathrm{C}$, and they all grow well at $35 \mathrm{C}$. This unique characteristic of hightemperature tolerance has not been found from other species in clade 9 or in members of any other Phytophthora clade. The monophyly of species in this high temperature-tolerant cluster, except $P$. insolita and $P$. polonica, is highly supported by the maximum-likelihood analyses of the ITS (99\%) and cox 1 (98\%) sequences (FIG. 2). Many species in this cluster including P. aquimorbida, P. hydropathica, $P$. irrigata and $P$. hydrogena initially were isolated from irrigation reservoirs. The host ranges of these aquatic species are unknown with the only exception of $P$. hydropathica, which is known to attack Kalmia latifolia and other horticultural crops (Hong et al. 2010). These findings might imply that the ancestors of these high temperature-tolerant species may originate from tropical or subtropical environments.

It is intriguing that all isolates of this novel species are A1. Similar observations were made in two other heterothallic species, P. hydropathica (Hong et al. 2010) and P. irrigata (Hong et al. 2008), that also were recovered initially from irrigation reservoirs in Virginia. The implication of this phenomenon remains unknown. One possibility is that two mating types of these heterothallic species were separated according to geographic distributions after their global migrations. This geographical separation of mating-type isolates has been reported in other Phytophthora species. For example, the A2 mating type of $P$. infestans was not found outside Mexico until 1984 (Hohl and Iselin 1984). Another example is all European isolates of $P$. ramorum before 2003 were A1 mating type while all North American isolates were A2 (Hansen et al. 2003). Similarly, it is possible that only A1 mating-type isolates of $P$. hydrogena, $P$. hydropathica and $P$. irrigata migrated from their origins to Virginia.

The economic and ecological significance of this new species is not clear at this point. Symptomatic plant samples infected by this species have never been recorded from the Disease Clinic at Hampton Road AREC, Virginia Tech, in Virginia Beach (C. Hong unpubl). P. hydrogena caused asymptomatic infection on roots of Rhododendron catawbiense, but it was a poor survivor in potting mix in a preliminary pathogenicity test (data not shown). Further studies are warranted on its host range, ecological role in aquatic and terrestrial ecosystems, as well as its origin.

\section{ACKNOWLEDGEMENTS}

This research was supported in part by grants from USDA/ NIFA (2005-51101-02337, 2010-51181-21140). We thank Dr Anton Baudoin and Dr Erik Stromberg for providing experimental equipment and technical advice on the morphological examinations performed in their labs. Our appreciation extends to Mrs Patricia Richardson for her assistance during the study and Mr. Xitong Li for his help with processing and editing figures for this manuscript.

\section{LITERATURE CITED}

Aghighi S, Hardy GESJ, Scott JK, Burgess TI. 2012. Phytophthora bilorbang sp. nov., a new species associated with the decline of Rubus anglocandicans (European blackberry) in Western Australia. Eur J Plant Pathol 133:841-855, doi:10.1007/s10658-012-0006-5

Ann PJ, Ko WH. 1980. Phytophthora insolita, a new species from Taiwan. Mycologia 72:1180-1185, doi:10.2307/ 3759572

Belbahri L, Moralejo E, Calmin G, Oszako T, Garcia JA, Descals E, Lefort F. 2006. Phytophthora polonica, a new species isolated from declining Alnus glutinosa stands in Poland. FEMS Microbiol Lett 261:165-174, doi:10.1111/ j.1574-6968.2006.00349.x

Blair JE, Coffey MD, Park S-Y, Geiser DM, Kang S. 2008. A multilocus phylogeny for Phytophthora utilizing markers derived from complete genome sequences. Fungal Genet Biol 45:266-277, doi:10.1016/j.fgb.2007.10.010

Bush EA, Hong CX, Stromberg EL. 2003. Fluctuations of Phytophthora and Pythium spp. in components of a recycling irrigation system. Plant Dis 87:1500-1506, doi:10.1094/PDIS.2003.87.12.1500

Cooke DEL, Drenth A, Duncan JM, Wagels G, Brasier CM. 2000. A molecular phylogeny of Phytophthora and related oomycetes. Fungal Genet Biol 30:17-32, doi:10.1006/fgbi.2000.1202

Crandall BS. 1947. A new Phytophthora causing root and collar rot of cinchona in Peru. Mycologia 39:218-223, doi: $10.2307 / 3755010$

Erwin DC, Ribeiro OK. 1996. Phytophthora diseases worldwide. St Paul, Minnesota: APS Press. 562 p.

Gallegly ME, Hong CX. 2008. Phytophthora: identifying species by morphology and DNA fingerprints. St Paul, Minneospta: APS Press. 158 p.

Ghimire SR, Richardson PA, Kong P, Hu J, Lea-Cox JD, Ross DS, Moorman GW, Hong CX. 2011. Distribution and diversity of Phytophthora species in nursery irrigation reservoir adopting water recycling system during winter months. J Phytopathol 159:713-719, doi:10.1111/ j.1439-0434.2011.01831.x

Goheen EM, Hansen EM, Kanaskie A, McWilliams MG, Osterbauer N, Sutton W. 2002. Sudden oak death caused by Phytophthora ramorum in Oregon. Plant Dis 86:441, doi:10.1094/PDIS.2002.86.4.441C

Grüenwald NJ, Werres S, Goss EM, Taylor CR, Fieland VJ. 2012. Phytophthora obscura sp. nov., a new species of the novel Phytophthora subclade 8d. Plant Pathol 61:610622, doi:10.1111/j.1365-3059.2011.02538.x 
Hansen EM, Reeser PW, Sutton W. 2012. Phytophthora borealis and Phytophthora riparia, new species in Phytophthora ITS Clade 6. Mycologia 104:1133-1142, doi:10.3852/11-349

,,--- Winton LM. 2003. First report of A1 mating type of Phytophthora ramorum in North America. Plant Dis 87:1267, doi:10.1094/PDIS.2003.87.10. 1267A

Hohl HR, Iselin K. 1984. Strains of Phytophthora infestans from Switzerland with A2 mating-type behavior. $\mathrm{T} \mathrm{Br}$ Mycol Soc 83:529-530, doi:10.1016/S0007-1536(84) 80057-1

Hong CX, Gallegly ME, Richardson PA, Kong P. 2011. Phytophthora pini Leonian resurrected to distinct species status. Mycologia 103:351-360, doi:10.3852/ $10-058$

— - — — — — Moorman GW. 2008. Phytophthora irrigata, a new species isolated from irrigation reservoirs and rivers in eastern United States of America. FEMS Microbiol Lett 285:203-211, doi:10.1111/j.1574-6968.2008.01226.x

, -,$-\longrightarrow$, Lea-Cox JD, Ross DS. 2010. Phytophthora hydropathica, a new pathogen identified from irrigation water, Rhododendron catawbiense and Kalmia latifolia. Plant Pathol 59:913-921, doi:10.1111/j.1365-3059.2010.02323.x

- - - Hao W, Ghimire SR, Kong P, Moorman GW, Lea-Cox JD, Ross DS. 2012. Phytophthora aquimorbida sp. nov. and Phytophthora taxon 'aquatilis' recovered from irrigation reservoirs and a stream in Virginia, USA. Mycologia 104:1097-1108, doi:10.3852/ 11-055

- — - Kong P. 2002. Comparison of membrane filters as a tool for isolating pythiaceous species from irrigation water. Phytopathology 92:610-616, doi:10.1094/ PНYТО.2002.92.6.610

Irwin JAG. 1991. Phytophthora macrochlamydospora, a new species from Australia. Mycologia 83:517-519, doi: $10.2307 / 3760365$

Jung T, Burgess TI. 2009. Re-evaluation of Phytophthora citricola isolates from multiple woody hosts in Europe and North America reveals a new species, Phytophthora plurivora sp. nov. Persoonia 22:95-110, doi:10.3767/ 003158509X442612

Ko WH. 1978. Heterothallic Phytophthora-evidence for hormonal regulation of sexual reproduction. J Gen Microbiol 107:15-18, doi:10.1099/00221287-107-1-15

Kong P, Hong CX, Richardson PA, Gallegly ME. 2003. Single-strand-conformation polymorphism of ribosomal DNA for rapid species differentiation in genus Phytophthora. Fungal Genet Biol 39:238-249, doi:10.1016/S1087-1845(03)00052-5

Kroon LPNM, Bakker FT, van den Bosch GBM, Bonants PJM, Flier WG. 2004. Phylogenetic analysis of Phytophthora species based on mitochondrial and nuclear DNA sequences. Fungal Genet Biol 41:766-782, doi:10.1016/j.fgb.2004.03.007

Man in 't Veld WA, de Cock A, Ilieva E, Levesque CA. 2002. Gene flow analysis of Phytophthora porri reveals a new species: Phytophthora brassicae sp. nov. Eur J Plant Pathol 108:51-62, doi:10.1023/A:1013929110325

Martin FN, Tooley PW. 2003. Phylogenetic relationships among Phytophthora species inferred from sequence analysis of mitochondrially encoded cytochrome oxidase I and II genes. Mycologia 95:269-284, doi: $10.2307 / 3762038$

Mostowfizadeh-Ghalamfarsa R, Cooke DEL, Banihashemi Z. 2008. Phytophthora parsiana sp. nov., a new hightemperature tolerant species. Mycol Res 112:783-794, doi:10.1016/j.mycres.2008.01.011

Naher M, Motohash K, Watanabe H, Chikuo Y, Senda M, Suga H, Brasier C, Kageyama K. 2011. Phytophthora chrysanthemi sp. nov., a new species causing root rot of chrysanthemum in Japan. Mycol Prog 10:21-31, doi:10.1007/s11557-010-0670-9

R Core Team. 2012. R: a language and environment for statistical computing. Vienna, Australia: R Foundation for Statistical Computing.

Rizzo DM, Garbelotto M, Davidson JM, Slaughter GW, Koike ST. 2002. Phytophthora ramorum as the cause of extensive mortality of Quercus spp. and Lithocarpus densiflorus in California. Plant Dis 86:205-214, doi:10.1094/PDIS.2002.86.3.205

Robideau GP, de Cock AWAM, Coffey MD, Voglmayr H, Brouwer H, Bala K, Chitty DW, Desaulniers N, Eggertson QA, Gachon CMM, Hu C-H, Kuepper FC, Rintoul TL, Sarhan E, Verstappen ECP, Zhang Y, Bonants PJM, Ristaino JB, Levesque CA. 2011. DNA barcoding of oomycetes with cytochrome $c$ oxidase subunit I and internal transcribed spacer. Mol Ecol Resour 11:1002-1011, doi:10.1111/j.1755-0998.2011. 03041.x

Tamura K, Nei M. 1993. Estimation of the number of nucleotide substitutions in the control region of mitochondrial DNA in humans and chimpanzees. Mol Biol Evol 10:512-526.

- Peterson D, Peterson N, Stecher G, Nei M, Kumar S. 2011. MEGA 5: molecular evolutionary genetics analysis using maximum likelihood, evolutionary distance, and maximum parsimony methods. Mol Biol Evol 28:27312739, doi:10.1093/molbev/msr121

Villa NO, Kageyama K, Asano T, Suga H. 2006. Phylogenetic relationships of Pythium and Phytophthora species based on ITS rDNA, cytochrome oxidase II and betatubulin gene sequences. Mycologia 98:410-422, doi:10.3852/mycologia.98.3.410

Warnes GR, Bolker B, Bonebakker L, Gentleman R, Liaw WHA, Lumley T, Maechler M, Magnusson A, Moeller S, Schwartz M, Venables B. 2012. gplots: various R programming tools for plotting data. In: Bolker B, Bonebakker L, Gentleman R, Liaw WHA, Lumley T, Maechler M, Magnusson A, Moeller S, Schwartz M, Venables B, eds. R package 2.11.0. http://CRAN. R-project.org $/$ package $=$ gplots

Waterhouse GM. 1963. Key to the Species of Phytophthora de Bary. Mycological Papers No. 92. Surrey, UK: Commonwealth Mycological Institute. 22 p. 